\title{
MAPEAMENTO DE ÁREAS LEGALMENTE PROTEGIDAS NO MUNICÍPIO DE TIBAU DO SUL/RN: UMA ANÁLISE A PARTIR DAS LEGISLAÇÕES FEDERAL, ESTADUAL E MUNICIPAL
}

\author{
Vitor Hugo Campelo Pereira \\ Universidade Federal do Rio Grande do Norte (UFRN), Departamento de Geografia, Natal, RN, Brasil \\ vitor.pereira95@yahoo.com.br \\ Luiz Antonio Cestaro \\ Universidade Federal do Rio Grande do Norte (UFRN), Departamento de Geografia, Natal, RN, Brasil \\ lacestaro@cchla.ufrn.br \\ Marco Túlio Mendonça Diniz \\ Universidade Federal do Rio Grande do Norte (UFRN), Departamento de Geografia, Caicó, RN, Brasil \\ tuliogeografia@gmail.com
}

\begin{abstract}
RESUMO
O presente artigo objetiva identificar e mapear os ambientes legalmente protegidos pela legislação ambiental nos âmbitos federal, estadual e municipal no município de Tibau do Sul/RN. A metodologia adotada baseia-se na análise da paisagem a partir da utilização de Sistemas de Informações Geográfica. Os resultados mostraram que cerca de $60 \%$ da área estudada é ocupada por ambiente legalmente protegidos: Mata Atlântica, dunas, manguezal, cursos d'água, entre outros. Apesar da importância ambiental e da proteção legal desses ambientes, os mesmos estão sendo ocupados e/ou sofrendo pressão em razão da ocupação do seu entorno.
\end{abstract}

Palavras-chave: Legislação Ambiental. Sistemas de Informações Geográficas. Tibau do Sul/RN.

\section{MAPPING OF LEGALLY PROTECTED AREAS IN THE MUNICIPALITY OF TIBAU DO SUL / RN: AN ANALYSIS THROUGH OF FEDERAL, STATE AND MUNICIPAL LEGISLATION}

\begin{abstract}
This article aims to identify and map the environments legally protected by environmental legislation at the federal, state and municipal levels of the municipality of Tibau do Sul / RN. The adopted methodology is based on the analysis of the landscape from the use of geographic information systems. The results show that about $60 \%$ of the studied area is occupied by a legally protected environment: Atlantic Forest, dunes, mangroves, water courses, among others. Despite the environmental importance and legal protection of the se areas, they are being occupied and / or under pressure due to the occupation of their surroundings.
\end{abstract}

Keywords: Environmental Laws. Geographic Information Systems. Tibau do Sul/RN.

\section{INTRODUÇÃO}

A proteção de determinados ambientes pela legislação ambiental brasileira se constitui como uma forma de gestão e proteção de espaços que apresentam recursos naturais e/ou culturais importantes. De acordo com a União Mundial para a Conservação da Natureza (IUCN), uma área protegida pode ser definida como um espaço geográfico claramente definido, reconhecido, dedicado e gerido, através de meios legais ou outros meios eficazes, para garantir a longo prazo a conservação da natureza, serviços dos ecossistemas e valores culturais associados (IUCN, 2008).

Em âmbito federal, a legislação voltada às áreas protegidas tem, historicamente, três principais instrumentos: O Código Florestal (Leis № 4771/1965 e № 12651/2012), o Sistema Nacional de Unidades de Conservação (SNUC) e algumas Resoluções do Conselho Nacional de Meio Ambiente (CONAMA).

Cada um desses instrumentos legislativos criou tipologias de áreas protegidas diferentes. Do Código Florestal foram originadas as Áreas de Preservação Permanente (APP's) e as Reservas Legais (RL's), enquanto que do SNUC surgiram as Unidades de Conservação de Proteção Integral (Estação

Caminhos de Geografia $\quad$ Uberlândia-MG $\quad$ v. 22, n. $82 \quad$ ago./2021 $\quad$ p.102-114 Página 102


Ecológica, Reserva Biológica, Parque Nacional, Monumento Natural, Refúgio de Vida Silvestre) e as Unidades de Conservação de Uso Sustentável (Área de Proteção Ambiental, Área de Relevante Interesse Ecológico, Floresta Nacional, Reserva Extrativista, Reserva de Fauna, Reserva de Desenvolvimento Sustentável, Reserva Particular do Patrimônio Natural).

Além dessas leis de origem federal, as legislações estadual e municipal complementam um sistema de áreas protegidas e são responsáveis pela indicação de proteção de ambientes que não estão previstos no escopo federal, ou ainda em alguns casos estabelecem restrições maiores do que as definidas no referido escopo. Em razão da relevância da temática, diversos iniciativas vêm sendo realizadas com intuito de espacializar e discutir a ocupação de áreas protegidas. Soares et al. (2011), Ribas e Gontijo (2015), Luppi et al. (2015), Eugenio et al. (2017), Oliveira e Francisco (2018), Ferretti (2019) são exemplos de estudos direcionados ao mapeamento de áreas protegidas, sobretudo no que diz respeito a identificação de APP (legislação federal).

No tocante às técnicas utilizadas nos estudos mencionados anteriormente, destaca-se o uso de ferramentas características da cartografia geomorfológica, como por exemplo: geração de Modelos Digitais de Elevação (MDE) e os mapeamentos de rede de drenagem, visando à identificação de APP relacionadas a topo de morros, declividade acima de 45, bem como para delineamento de cursos d'água. Para o mapeamento do uso do solo/vegetação, a classificação supervisionada por Máxima Verossimilhança (MAXVER) está presente em diversos estudos voltados à identificação de Áreas legalmente protegidas. A classificação orientada a objetos também é aplicada para estudos dessa natureza, estando presente em Nunes e Roig (2015) e Macedo e Moreau (2019).

Os municípios localizados no litoral brasileiro, ao longo da história, vêm sofrendo as consequências da ocupação desordenada, da expansão agrícola e, sobretudo, em períodos mais recentes da forte exploração turística e de uma expansão imobiliária bastante aquecida.

O município de Tibau do Sul/RN, localizado no litoral sul do estado do Rio Grande do Norte apresenta um quadro natural composto por recursos naturais importantes, como campos dunares e manguezais, mas que estão sendo modificados pela ampliação de áreas voltadas ao desenvolvimento de atividades agrícolas, aquicultura e pela expansão imobiliária, que é motivada principalmente pela intensa atividade turística praticada no município.

O planejamento territorial municipal deve considerar as áreas legalmente protegidas, definindo restrições e potencialidades de acordo com as características de cada ambiente natural ou cultural. Nesse contexto, cresce a importância de se pensar a ocupação do território de forma que os recurs os naturais e culturais possam ser aproveitados sustentavelmente, garantindo assim o usufruto dos mesmos pelas gerações futuras.

A delimitação clara e precisa dessas áreas se constitui como elemento fundamental para o planejamento ambiental, pois pode subsidiar a ocupação do solo de maneira adequada, contribuindo com a sua preservação ou conservação.

Os limites dos ambientes legalmente protegidos devem ser delimitados para que sejam reconhecidos e para isso, os Sistemas de Informação Geográfica (SIG's) podem ser utilizados como uma ferramenta para a análise espacial e consequentemente para fins de espacialização das áreas protegidas pela legislação ambiental.

O termo Sistema de Informação Geográfica (SIG), de maneira geral, é utilizado para sistemas que realizam o tratamento computacional de dados geográficos e recuperam as informações não apenas com base em suas características alfanuméricas, mas também através de sua localização espacial (CAMARA; DAVIS, 2002).

Neste sentido, o presente artigo objetiva identificar e delimitar as áreas protegidas no município de Tibau do Sul/RN, sob o ponto de vista da legislação ambiental vigente nas esferas municipal, estadual e federal.

\section{ÁREA DE ESTUDO}

O recorte espacial adotado pela pesquisa é o município de Tibau do Sul/RN (Figura 1), cujas coordenadas geográficas de seu ponto central são: $6^{\circ} 11^{\prime} 12^{\prime \prime}$ Sul e $35^{\circ} 05^{\prime} 31^{\prime \prime}$ Oeste, estando localizado na Região Geográfica Imediata de Canguaretama e distando $72 \mathrm{~km}$ da capital do estado do Rio Grande do Norte, Natal. Limita-se ao Norte pelo município de Senador Georgino Avelino e o

Caminhos de Geografia Uberlândia-MG $\quad$ v. 22, n. $82 \quad$ ago./2021 $\quad$ p.102-114 Página 103


Oceano Atlântico; Ao sul pelos municípios de Vila Flor e Canguaretama; À leste pelo Oceano Atlântico e à Oeste pelos municípios de Arês e Goianinha.

Figura 1 - Mapa de localização do município de Tibau do Sul/RN.

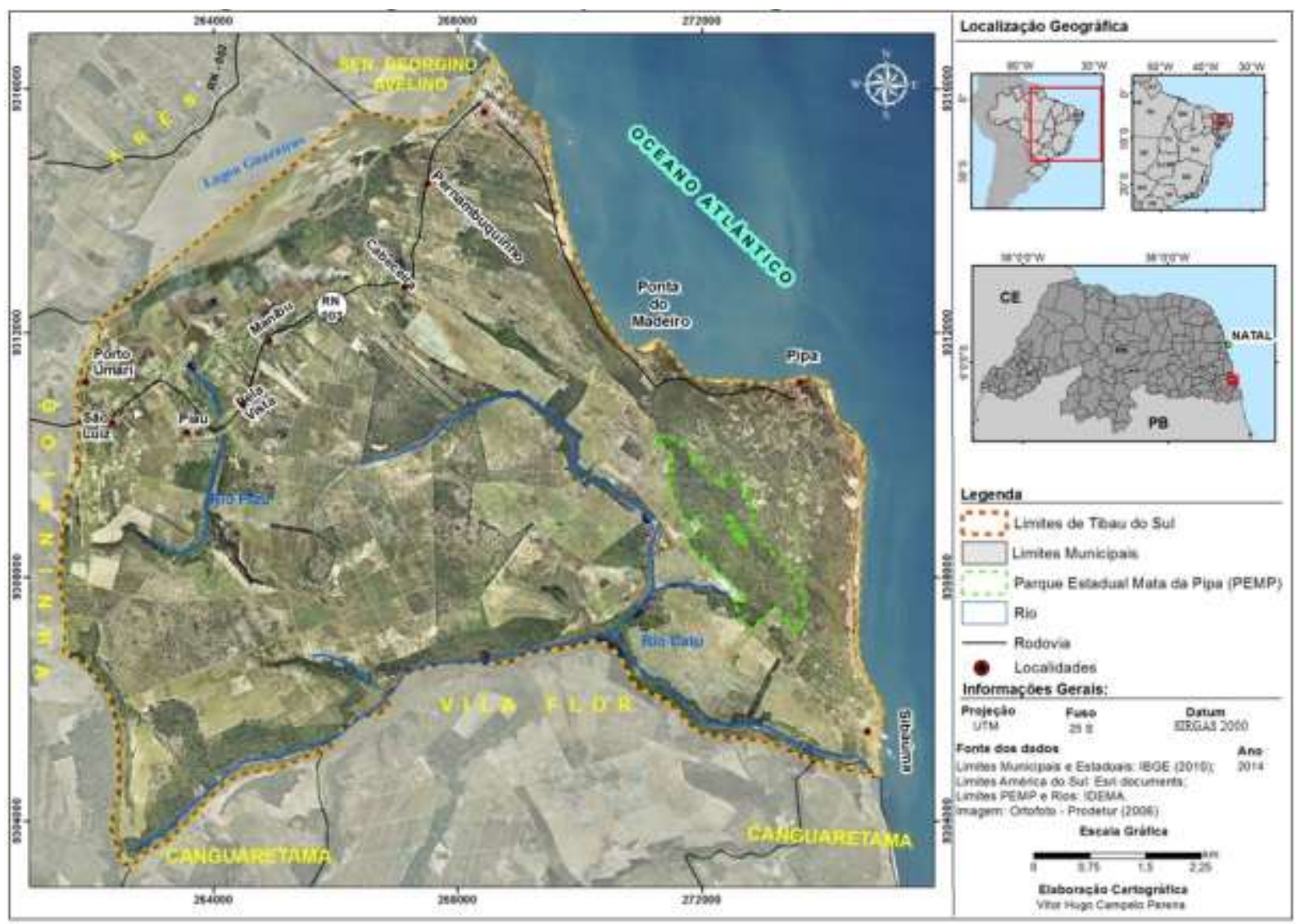

Fonte - Elaborado pelos autores.

No tocante às características físicas, o referido município apresenta um quadro natural bastante diversificado, caracterizado pela abrangência do clima tropical, apresentando temperaturas anuais máxima, média e mínima de $32^{\circ} \mathrm{C}, 25,6^{\circ} \mathrm{C}$ e $21^{\circ} \mathrm{C}$, respectivamente, tendo como período chuvoso o intervalo entre os meses de janeiro e agosto (IDEMA, 2008).

Do ponto de vista geológico, segundo Oliveira (2011), o município apresenta as seguintes litologias: Depósitos Aluvionares, Depósitos Colúvio-Eluviais, Depósitos Eólicos Litorâneos de Paleodunas, Depósitos Flúvio-Lacustrinos, Depósitos Litorâneos de Praia e Dunas Móveis, Depósitos de Mangue e a Formação Barreiras, sendo predominantes as litologias associadas aos Depósitos Colúvio -Eluviais, Formação Barreiras e Depósitos Eólicos Litorâneos de Paleodunas.

No que diz respeito à sua geomorfologia, o município apresenta relevo predominantemente plano nas faixas compreendidas pelos Tabuleiros Costeiros e planícies fluviais, flúvio-lacustrina e flúviomarinha, e bastante ondulado nas áreas ocupadas pelos campos dunares. Além disso, a altimetria varia em média de $0 \mathrm{~m}$ a $85 \mathrm{~m}$ e as declividades estão entre $0^{\circ}$ e $83^{\circ}$, estando os maiores valores localizados nos campos dunares, nas falésias e nas vertentes próximas aos cursos d'água.

Em relação aos solos, são encontrados no município as seguintes formações: Areias Quartzosas/Areias Quartzosas Marinhas ou Neossolos Quartzarênicos, Podzólico Vermelho-Amarelo Distrófico, Solos Aluviais (Luvissolos) e Indiscriminados de Mangue, sendo os Neossolos Quartzarênicos a formação predominante (OLIVEIRA, 2011).

Caminhos de Geografia Uberlândia-MG $\quad$ v. 22, n. $82 \quad$ ago./2021 $\quad$ p.102-114 Página 104


No tocante à vegetação, o município está inserido na área de abrangência do bioma Mata Atlântica, possuindo segundo Brasil (1981), remanescentes das fisionomias Floresta Estacional Semidecidual e Restingas Arbustiva e Herbácea (Floresta Esclerófila). No que diz respeito à hidrografia, estão localizados na área de estudo os rios Catu e Piau, além da Lagoa de Guaraíras, que por sua vez é um ambiente prioritário para conservação, que integra a Área de Proteção Ambiental (APA) Bonfim/Guaraíras. A partir da Figura 2 é possível visualizer, de forma espacializada, uma síntese acerca do quadro físico da área de estudo.

Figura 2 - Síntese do quadro físico do município de Tibau do Sul/RN.

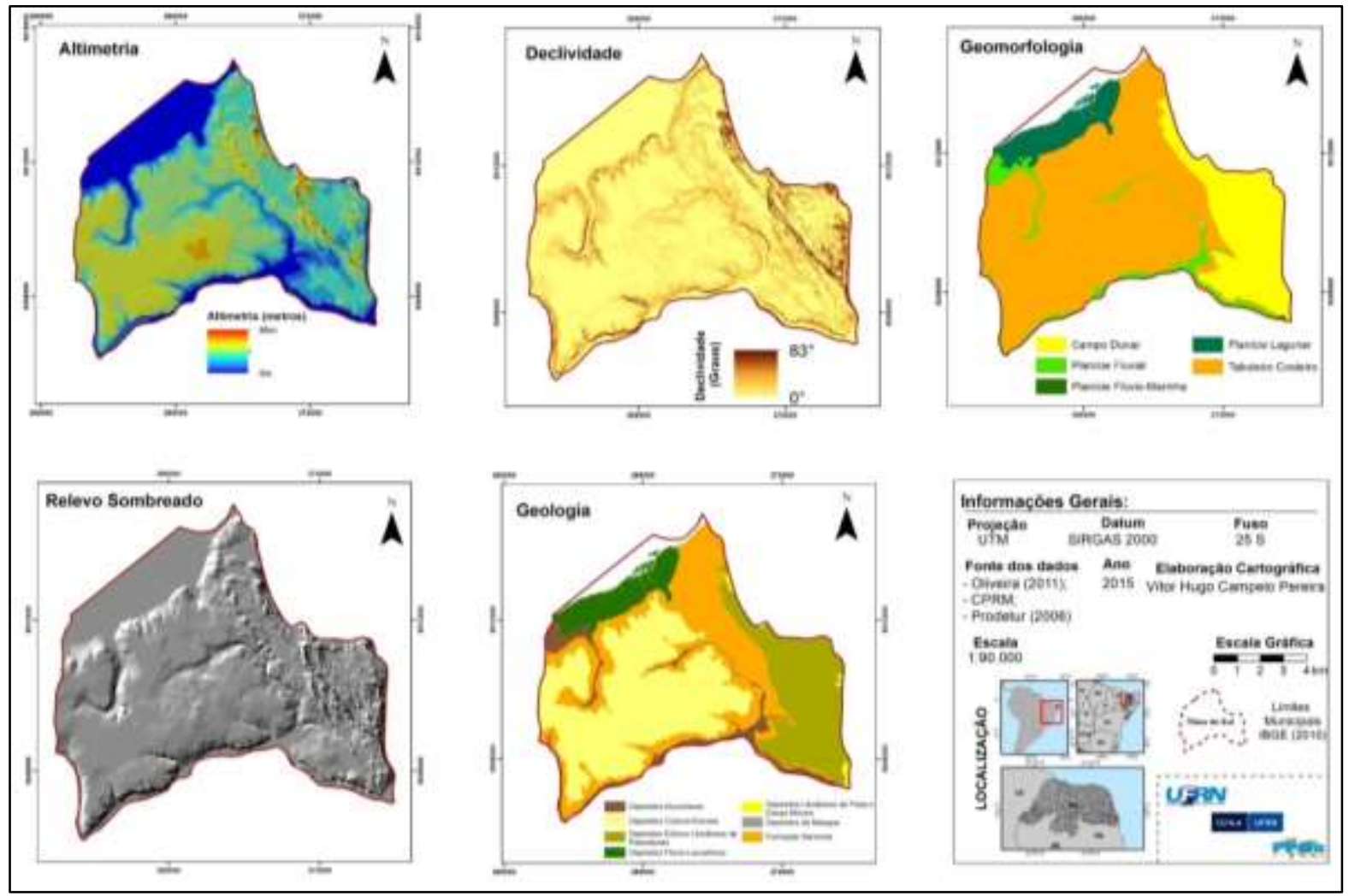

Fonte - Elaborado pelos autores.

Sob a perspectiva socioeconômica, a área de estudo possui uma população de 11.385 habitantes, dos quais $6.861(60,26 \%)$ residem em área urbana e predominantemente estão na faixa de idade adulta (IBGE, 2010). O rendimento mensal predominante é de mais de meio salário mínimo até 1 salário mínimo, tomando por base o salário de $\mathrm{R} \$ 510,00$. Em relação ao Produto Interno Bruto (PIB), o setor de maior participação é o de serviços, em razão especialmente, da forte participação do turismo desenvolvido no município.

No que concerne à produção agrícola, o município possui atividades de características permanentes e temporárias. As culturas permanentes desenvolvidas na área são: maracujá, castanha de caju, laranja, banana, manga e coco-da-baía, sendo essa última a que abrange as maiores porções de área dentre as culturas permanentes. De caráter temporário são desenvolvidas as culturas do milho, feijão e da cana-de-açúcar, esta por sua vez está presente em grande parte do município.

\section{MATERIAIS E MÉTODOS}

A metodologia do presente estudo pode ser subdividida em duas etapas. A primeira etapa refere-se à identificação das áreas naturais da área de estudo, através da interpretação de imagens orbitais e aerofotos, visando o mapeamento dessas áreas, através do uso de SIG.

Caminhos de Geografia Uberlândia-MG $\quad$ v. 22, n. $82 \quad$ ago./2021 $\quad$ p. 102-114 Página 105


Na terceira etapa foi realizada a delimitação das áreas protegidas, através de operações de análise espacial e também foram produzidos os mapas que serviram de base para as análises e discussões do estudo. A Figura 3 representa as duas, previstas na metodologia.

Figura 3 - Fluxograma contendo as etapas da metodologia.

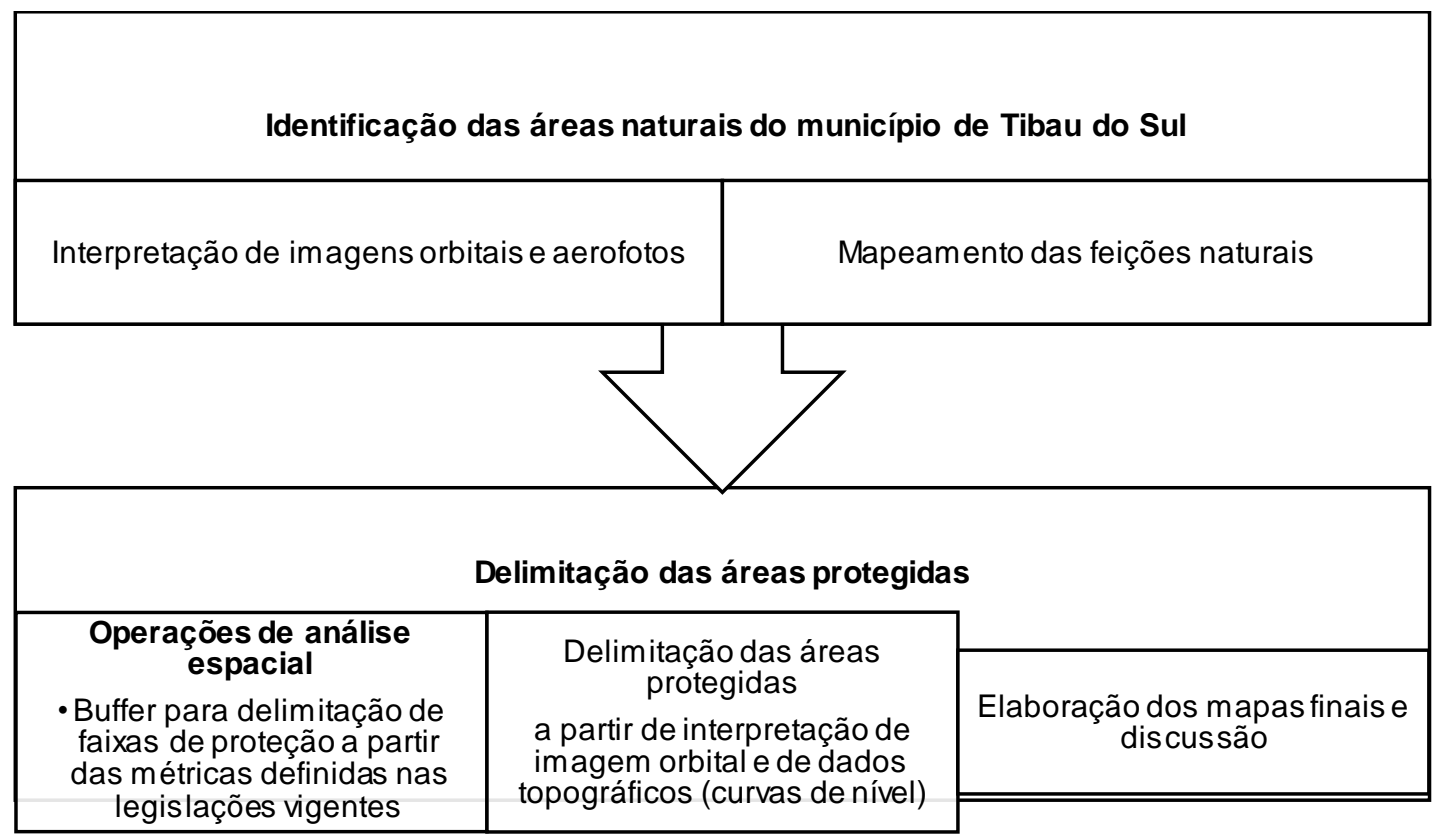

Fonte - Elaborado pelos autores.

Após o levantamento sobre a legislação ambiental incidente sobre o município de Tibau do Sul/RN, foram selecionadas como referência leis que definem áreas protegidas nas esferas municipal, estadual e federal.

No âmbito municipal, a referência legislativa adotada foi o Código Municipal de Meio Ambiente de Tibau do Sul, Lei Municipal № 383/2008 (CMMATS,2008). Nessa lei, as áreas protegidas são: faixas de $100 \mathrm{~m}, 200 \mathrm{~m}$ e $300 \mathrm{~m}$ de largura no entorno de todo o Parque Estadual da Mata da Pipa (PEMP); Corredores Ecológicos (faixa de $50 \mathrm{~m}$ às margens dos rios interiores, contada a partir da maior cheia) e áreas de controle de erosão e manutenção de exultórios.

No âmbito estadual, os ambientes protegidos estão previstos no Zoneamento Ecológico -Econômico do Litoral Oriental do Rio Grande do Norte: Lei № 7.871/2000 (RIO GRANDE DO NORTE, 2000) e no Plano Estadual de Gerenciamento Costeiro: Lei № 6.950/1996 (RIO GRANDE DO NORTE, 1996) Manguezal em toda a sua extensão; lagoas e demais mananciais, Mata Atlântica; dunas vegetadas ou não; restingas; brejos e áreas úmidas.

No âmbito federal, a legislação base é o Código Florestal: Leis № 12.651/2012 e № 12.727/2012 (BRASIL, 2012). Os ambientes previstos referem-se às Áreas de Preservação Permanente (APP): faixa de 50 (cinquenta) metros, para os cursos d'água que tenham de 10 (dez) a 50 (cinquenta) metros de largura; encostas ou partes destas com declividade superior a $45^{\circ}$, equivalente a $100 \%$ (cem por cento) na linha de maior declive; restingas, como fixadoras de dunas ou estabilizadoras de mangues; manguezais, em toda a sua extensão; bordas dos tabuleiros ou chapadas, até a linha de ruptura do relevo, em faixa nunca inferior a 100 (cem) metros em projeções horizontais. As áreas protegidas identificadas estão agrupadas no Quadro 1, com suas respectivas descrições. 
Quadro 1 - Áreas protegidas no município de Tibau do Sul/RN .

\begin{tabular}{|c|c|c|c|}
\hline $\begin{array}{c}\text { Ámbito } \\
\text { legislativo }\end{array}$ & Lei & Tipo de ambiente & Descrição \\
\hline Municipal & $\begin{array}{l}\text { Código Municipal de } \\
\text { Meio Ambiente de } \\
\text { Tibau do Sul (Lei } \\
\text { Municipal } \\
\text { 383/2008) }\end{array}$ & $\begin{array}{l}\text { - área de controle de } \\
\text { erosão e manutenção de } \\
\text { exultórios; } \\
\text { - faixas de } 100 \mathrm{~m}, 200 \mathrm{~m} \\
\text { e } 300 \mathrm{~m} \text { de largura no } \\
\text { entorno de todo o } \\
\text { Parque Estadual da } \\
\text { Mata da Pipa; } \\
\text { - corredores ecológicos } \\
\text { (faixa de 50m às } \\
\text { margens dos rios } \\
\text { interiores, contada a } \\
\text { partir da maior cheia). }\end{array}$ & $\begin{array}{l}\text { As áreas de controle de erosão e manutenção } \\
\text { de exultórios: são "áreas passíveis de remoção } \\
\text { de sedimentos e inundações por processos } \\
\text { naturais ou induzidos, bem como de } \\
\text { escoamento difuso da planície de inundação } \\
\text { através dos exultórios" (PMTS, 2008). } \\
\text { Segundo essa Lei, a faixa de 100m de largura } \\
\text { no entorno de todo o Parque Estadual da Mata } \\
\text { da Pipa se constitui como uma área de restrição } \\
\text { intensa, ou seja, de alta restrição para o uso e } \\
\text { ocupação do solo. } \\
\text { Por essa Lei, os corredores ecológicos são } \\
\text { reconhecidos como áreas de preservação } \\
\text { permanente, cabendo aos proprietários privados } \\
\text { e ao poder público o dever de proteger essas } \\
\text { áreas, não permitindo qualquer supressão } \\
\text { vegetal em seus limites. }\end{array}$ \\
\hline \multirow[t]{2}{*}{ Estadual } & $\begin{array}{l}\text { Zoneamento } \\
\text { Ecológico-Econômico } \\
\text { do Litoral Oriental do } \\
\text { Rio Grande do Norte } \\
\text { (Lei № } 7.871 / 2000)\end{array}$ & $\begin{array}{l}\text { - Manguezal em toda a } \\
\text { sua extensão; } \\
\text { - Mata Atlântica; } \\
\text { - mata Ciliar; } \\
\text { - falésias; } \\
\text { - nascentes dos corpos } \\
\text { d'água de superfície, } \\
\text { lagoas e demais } \\
\text { mananciais; cobertura } \\
\text { - dunas, com com } \\
\text { vegetal; sem cobertura } \\
\text { - dunas sem de } \\
\text { vegetal, julgadas de } \\
\text { importância ambiental } \\
\text { pelo órgão competente, } \\
\text { tendo por base estudos } \\
\text { técnicos; }\end{array}$ & $\begin{array}{l}\text { No Art. } 9 \text { desssa Lei, esses ambientes são } \\
\text { considerados Áreas de Preservação (AP's), que } \\
\text { consistem em áreas nas quais as características } \\
\text { do meio físico restringem o uso e ocupação, } \\
\text { visando à proteção, manutenção e recuperação } \\
\text { dos aspectos paisagísticos, históricos, } \\
\text { arqueológicose científicos. }\end{array}$ \\
\hline & $\begin{array}{l}\text { Plano Estadual de } \\
\text { Gerenciamento } \\
\text { Costeiro (Lei № } \\
6.950 / 1996)\end{array}$ & $\begin{array}{l}\text { - dunas, com ou sem } \\
\text { cobertura vegetal; } \\
\text { - restingas; } \\
\text { - manguezais; } \\
\text { - brejos e áreas úmidas; } \\
\text { - matas ciliares. }\end{array}$ & $\begin{array}{l}\text { No Art. } 20 \text { dessa Lei, esses ambientes são } \\
\text { concebidos como áreas de preservação, por } \\
\text { serem ecossistemas frágeis componentes da } \\
\text { Reserva da Biosfera da Mata Atlântica. }\end{array}$ \\
\hline Federal & $\begin{array}{l}\text { Código Florestal e } \\
\text { suas atualizações } \\
\text { (Leis № } 4.771 / 1965 \text {, } \\
\text { № } 12.651 / 2012 \text { e № } \\
12.727 / 2012 \text { ) }\end{array}$ & $\begin{array}{l}\text { - faixa de } 50 \text { (cinquenta) } \\
\text { metros, para os cursos } \\
\text { d'água que tenham de } \\
10 \text { (dez) a } 50 \\
\text { (cinquenta) metros de } \\
\text { largura; } \\
\text { - encostas ou partes } \\
\text { destas com declividade } \\
\text { superior a } 45^{\circ} \text {, } \\
\text { equivalente a } 100 \% \\
\text { (cem por cento) na linha } \\
\text { de maior declive; } \\
\text { - restingas, como } \\
\text { fixadoras de dunas ou } \\
\text { estabilizadoras } \\
\text { mangues; } \\
\text { - manguezais, em toda a } \\
\text { sua extensão; } \\
\text { - bordas dos tabuleiros } \\
\text { ou chapadas, até a linha } \\
\text { de ruptura do relevo, em } \\
\text { faixa nunca inferior a } \\
100 \text { (cem) metros em } \\
\text { projeções horizontais; }\end{array}$ & $\begin{array}{l}\text { No Art. } 4 \text { da Lei } 12.651 / 2012 \text {, esses ambientes } \\
\text { são considerados Áreas de Preservação } \\
\text { Permanente (APP), definidas pela mesma Lei } \\
\text { como:" área protegida, coberta ou não por } \\
\text { vegetação nativa, com a função ambiental de } \\
\text { preservar os recursos hídricos, a paisagem, a } \\
\text { estabilidade geológica e a biodiversidade, } \\
\text { facilitar o fluxo gênico de fauna e flora, proteger } \\
\text { o solo e assegurar o bem-estar das populações } \\
\text { humanas" (BRASIL, 2012). }\end{array}$ \\
\hline
\end{tabular}

Fonte - Elaborado pelos autores. 
Os diferentes tipos de ambientes protegidos pela legislação foram obtidos, através de técnicas e insumos distintos. Os ambientes: Manguezal, dunas vegetadas ou não, brejos e áreas úmidas foram mapeados a partir de interpretação e vetorização de feições com base em imagem do satélite Kompsat 3/AEISS (07 de maio de 2015) e curvas de nível de $5 \mathrm{~m}$ de equidistância oriundas de ortofotos do ano de 2006, cedidas pelo Programa de Desenvolvimento do Turismo (PRODETUR).

Em relação à imagem orbital, foram utilizadas duas cenas na órbita de número 11381, com elevação solar de 52,14 no momento de captura das imagens. As referidas imagens são captadas em 5 bandas espectrais (vermelho, verde, azul, infravermelho próximo e pancromático), com resolução espacial de 2,8 $\mathrm{m}$ na faixa multiespectral e de $0,7 \mathrm{~m}$ na banda pancromática (Tabela 1).

Tabela 1 - Características do sensor KOMPSAT 3/AEISS.

\begin{tabular}{|c|c|c|c|}
\hline Faixa espectral & Resolução espectral & Resolução Espacial & Resolução radiométrica \\
\hline Pancromático & $450-900 \mathrm{~nm}$ & 0,7 metros & \multirow{5}{*}{14 bits } \\
\hline$\overline{\text { Azul }}$ & $450-520 \mathrm{~nm}$ & \multirow{4}{*}{2,8 metros } & \\
\hline Verde & $520-600 \mathrm{~nm}$ & & \\
\hline Vermelho & $630-690 \mathrm{~nm}$ & & \\
\hline Infravermelho Próximo & $760-900 \mathrm{~nm}$ & & \\
\hline
\end{tabular}

Para serem utilizadas, as imagens supracitadas passaram por processamento digital, com operaçõ es de correções atmosférica e radiométrica, além da operação de realce de contraste do tipo linear com o objetivo de aumentar a discriminação visual dos objetos da imagem.

Foram mapeados a partir de interpretação da imagem supracitada e da utilização da operação de "expansão de vizinhança" (buffer), na plataforma SIG ArcGls 10.4, os ambientes: faixa de 100m de largura no entorno de todo o Parque Estadual da Mata da Pipa, corredores ecológicos (faixa de 50m às margens dos rios interiores, contada a partir da maior cheia), faixa de 50 (cinquenta) metros, para os cursos d'água que tenham de 10 (dez) a 50 (cinquenta) metros de largura, bordas dos tabuleiros ou chapadas, até a linha de ruptura do relevo, em faixa nunca inferior a 100 (cem) metros em projeções horizontais.

Os ambientes protegidos por estarem situados em encostas ou partes destas com declividade superior a $45^{\circ}$, equivalente a $100 \%$ (cem por cento) na linha de maior declive, foram mapeados, através da geração de mapa clinográfico (declividade) no software ArcGIS 10.4 (módulo 3D Analyst), com base em curvas de nível de $5 \mathrm{~m}$ de equidistância (PRODETUR).

\section{RESULTADOS E DISCUSSÃO}

Após análise e processamento dos dados em ambiente SIG, foi possível identificar e delimitar os ambientes protegidos pela legislação ambiental nos âmbitos federal, estadual e municipal.

Ao todo, aproximadamente $60 \%(59,7 \%)$ da área do município é composta por ambientes legalmente protegidos. Alguns desses ambientes estão previstos em mais de um âmbito legislativo, como é o caso do manguezal, resguardado nos domínios federal e estadual. Além disso, cabe destacar que alguns ambientes são espacialmente semelhantes, como é o caso das faixas de proteção de $30 \mathrm{~m}$ ao longo dos rios (legislação federal) e os corredores ecológicos (legislação municipal).

As Figuras 4 e 5 representam a espacialização de todos os ambientes legalmente protegidos no município de Tibau do Sul/RN. Cabe ressaltar que área original desses ambientes foi e está sendo modificada, de forma que para os mapeamentos foram consideradas apenas a extensão atual.

${ }^{1}$ https://www.kari.re.kr/ 
Figura 4 - Áreas legalmente protegidas do município de Tibau do Sul/RN.

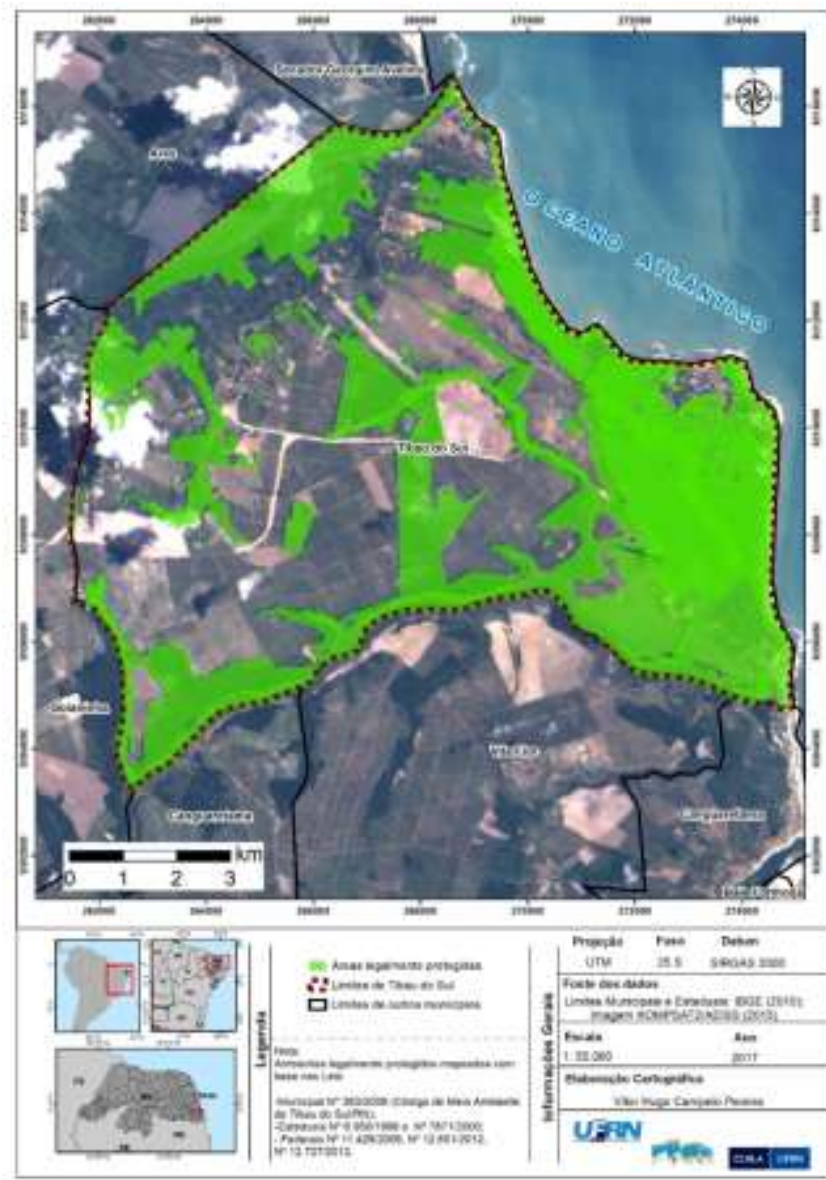

Fonte - Elaborado pelos autores.

Figura 5 - Tipologia das áreas protegidas pela legislação no município de Tibau do Sul/RN .

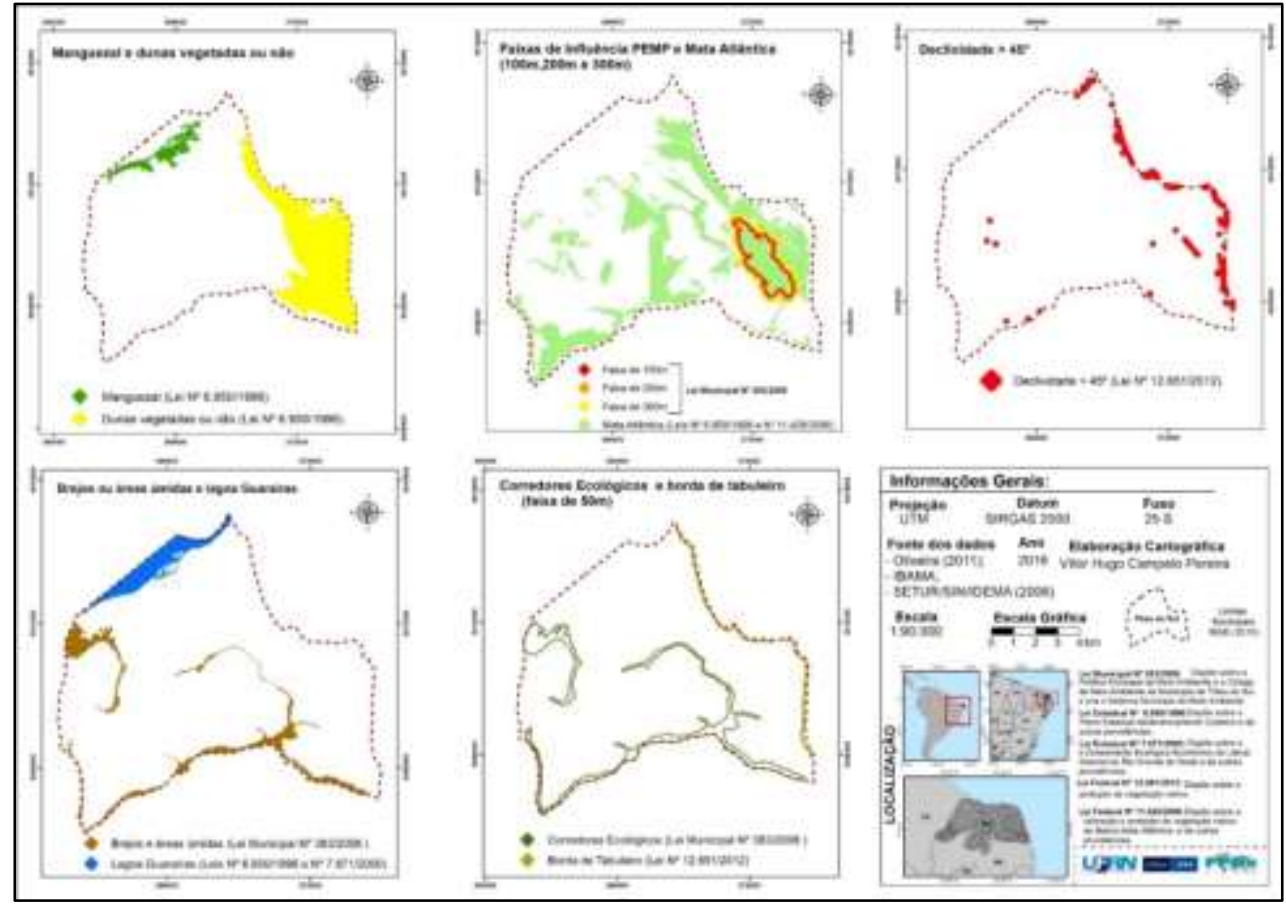

Fonte - Elaborado pelos autores. 
Faz-se necessária uma breve caracterização sobre alguns dos ambientes identificados, a destacar: faixas de distância no entorno do PEMP, Corredores Ecológicos, brejos e áreas úmidas, áreas de controle à erosão e manutenção de exultórios, manguezais, faixa de $50 \mathrm{~m}$ ao longo de rios que tenham de $10 \mathrm{~m}$ a $50 \mathrm{~m}$ de largura e as bordas de tabuleiro.

As faixas de distância no entorno do PEMP dizem respeito a áreas que apresentam ressalvas quanto a seu uso. As faixas de $100 \mathrm{~m}, 200 \mathrm{~m}, 300 \mathrm{~m}$ são denominadas de uso intenso, uso semi-intenso e externa, respectivamente. Constituindo áreas que possuem restrições quanto a seu uso, que aumentam nas faixas mais próximas ao PEMP.

Os Corredores Ecológicos concebidos pelo Código Municipal de Meio Ambiente de Tibau do Sul (CMMTS) são áreas que ocupam faixas de $50 \mathrm{~m}$ às margens dos rios interiores, contadas a partir da maior cheia, sendo a conservação dessas áreas de responsabilidade tanto do Poder Público quanto dos proprietários particulares de terra.

As áreas de controle à erosão e manutenção de exultórios são espacialmente equivalentes às planícies fluviais/áreas úmidas e de brejo, que por sua vez se constituem como ambientes periodicamente inundáveis, localizados ao longo de rios ou em topografias baixas e planas.

Os manguezais correspondem a ecossistemas litorâneos que ocorrem "em terrenos baixos, sujeitos à ação das marés, formado por vasas lodosas recentes ou arenosas, às quais se associa, predominantemente, a vegetação natural conhecida como mangue, com influência fluviomarinha" (BRASIL, 2012).

As faixas de $50 \mathrm{~m}$ ao longo dos rios que tenham de $10 \mathrm{~m}$ a $50 \mathrm{~m}$ de largura (característico da área de estudo) são consideradas Áreas de Preservação Permanente (APP), cujo regime de proteção é integral. Cabe destacar que no mapeamento realizado, essas áreas foram englobadas pelas áreas úmidas e de brejo.

As bordas de Tabuleiro correspondem à linha de ruptura do relevo inerente aos Tabuleiros Costeiros, especialmente nas escarpas de falésia. Essa área deve ser delimitada e protegida levando em consideração a faixa equivalente a $100 \mathrm{~m}$ partindo da referida linha de ruptura de relevo em direção ao continente. Em relação ao nível de proteção das áreas consideradas pelo modelo, todas se constituem como ambientes de proteção integral, com exceção das faixas de $100 \mathrm{~m}, 200 \mathrm{~m}, 300 \mathrm{~m}$ no entorno do PEMP, que possuem proteção gradativa, sendo tão mais intensas quanto mais próximas do Parque.

A maior parte $(2.910,18$ hectares) das áreas protegidas no município de Tibau do Sul/RN é composta pelos fragmentos de Mata Atlântica e fisionomias associadas, como o manguezal (263,18 hectares). Os remanescentes de Mata Atlântica têm sua proteção resguardada pelas Leis Estaduais № 6.950/1996, № 7871/2000 e Lei Federal 11.428/2006 (Lei da Mata Atlântica). Na Figura 6 está representada a distribuição dos valores das áreas ocupadas em hectares por cada ambiente legalmente protegido na área de estudo. Cabe ressaltar que em razão de existirem áreas protegidas que são espacialmente coincidentes, como dunas vegetadas ou não e algumas fisionomias associadas à Mata Atlântica, não seria indicada a apresentação de percentuais dessas áreas em relação à suas extensões na área de estudo.

Figura 6 - Área em hectares ocupada por cada ambiente legalmente protegido no município de Tibau do Sul/RN.

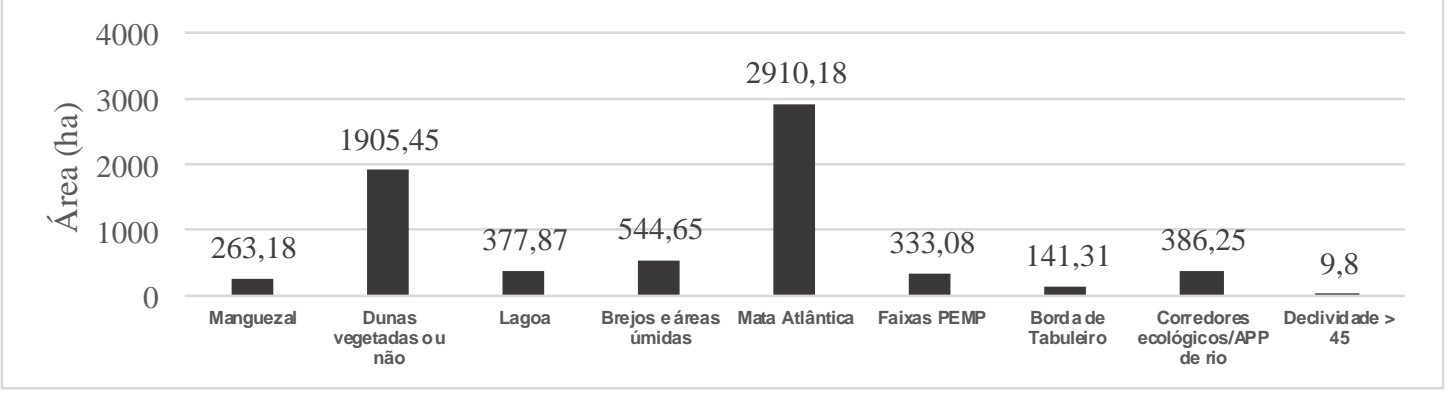

Fonte - Elaborado pelos autores.

Esses ambientes protegidos conformam paisagens bastante diversificadas, que se diferenciam não apenas sob o ponto de vista cênico, mas também no que diz respeito a dinâmica ambiental dos mesmos. Na Figura 7 é possível verificar as distintas paisagens características desses ambientes. 
Figura 7 - [1] Borda de tabuleiro e área com declividade > 45; [2] Lagoa de Guaraíras; [3] Manguezal; [4] Brejos e áreas úmidas, mata ciliar e corredores ecológicos; [5] Dunas vegetadas ou não; [6] Restinga (Mata Atlântica).

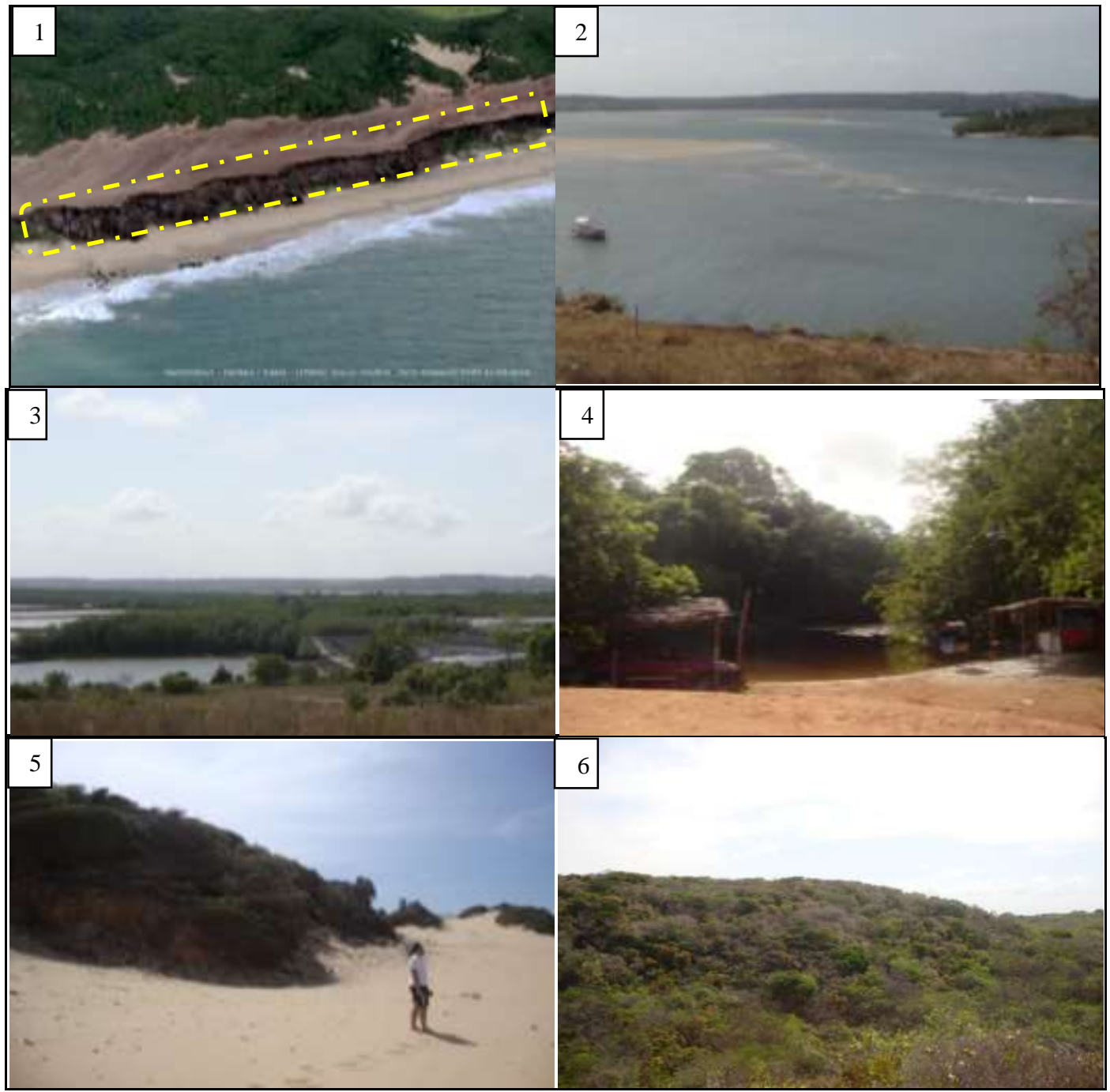

Fotos - Autores, ano 2018 [2,3,4,5,6] e IDEMA, ano 2010 [1].

Embora todos sejam considerados ambientes legalmente protegidos. Do ponto de vista da dinâmica ambiental, é importante ressaltar que essas áreas apresentam características diferentes e reagem de maneira variada a pressão exercida pelo homem. As fragilidades e potencialidades são diversas e devem ser consideradas no ordenamento territorial municipal.

Em todo território nacional o bioma Mata Atlântica vem sendo devastado e fragmentado, De acordo com Dean (1996), a história da fragmentação da Mata Atlântica no Brasil sempre esteve associada aos ciclos econômicos vivenciados pelo país. Atualmente, as principais ameaças a esse bioma são a dilatação das fronteiras agrícolas e a expansão imobiliária (ALEIXO et. al, 2010).

Das áreas identificadas e mapeadas, a Mata Atlântica é o ambiente protegido que ocupa as maiores porções da área de estudo. Cabe ressaltar que as fisionomias associadas a esse bioma (manguezal, floresta estacional e restinga/dunas vegetadas) sofrem pressão da ocupação e expansão de atividades relacionadas à carcinicultura, expansão turística e cultura canavieira. A Figura 8 é um exemplo de como a expansão imobiliária associada à atividade turística vem alterando a composição original desse ambiente protegido no município de Tibau do Sul/RN. É possível visualizar a ocupação de áreas de Mata Atlântica por estruturas típicas de hotéis, resorts e pousadas. 
Figura 8 - Ocupação turística em área de Mata Atlântica no município de Tibau do Sul/RN.

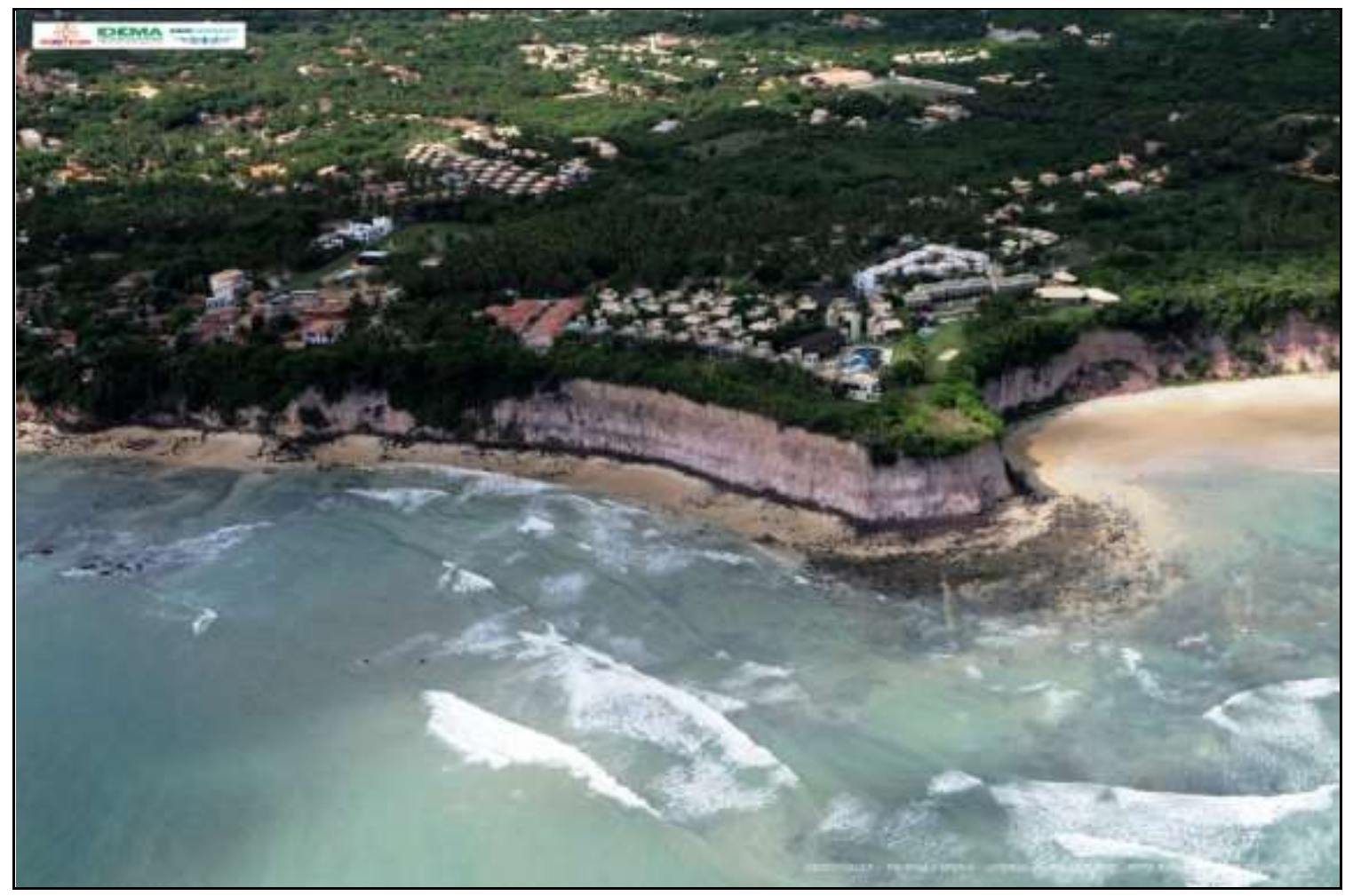

Fonte - Instituto de Desenvolvimento e Meio Ambiente do Rio Grande do Norte, ano 2010.

Das áreas legalmente protegidas, que foram identificadas e mapeadas, verifica-se que a Mata Atlântica apresenta maiores riscos de devastação, em razão dos cenários futuros que podem ser projetados a partir da dinâmica de uso e ocupação do solo no município de Tibau do Sul/RN. Neste sentido, é de relevante importância que o poder público em todas as esferas possa criar mecanis mos de fiscalização ef etiva e desenvolvimento de programas e projetos, visando à proteção e recuperação desses ambientes.

\section{CONSIDERAÇÕES FINAIS}

O ordenamento territorial municipal deve conceber os ambientes legalmente protegidos a partir de suas potencialidades e fragilidades, a fim de conciliar a conservação da natureza e 0 desenvolvimento sustentável.

Após análise da legislação ambiental vigente, verificou-se que o município de Tibau do Sul/RN apresenta uma grande variedade de ambientes protegidos. Dessa forma, qualquer atividade de planejamento que envolva alterações sobre o uso do solo deve considerar tais elementos previstos pela lei.

A metodologia adotada se mostrou eficiente, tomando por base os objetivos propostos pelo estudo. Os Sistemas de Informação Geográfica se constituem como uma importante ferramenta para investigações dessa natureza, dada as diversas possibilidades oferecidas no que tange a mensurações e combinações de informações espaciais.

É proeminente que a gestão ambiental municipal com auxílio das outras esferas administrativas atue na criação de um banco de dados com informações ambientais, que possam servir p ara o controle e manutenção dos ambientes legalmente protegidos. Além disso, deve propor programas de conscientização ambiental, que tenham ênfase na disseminação de ações voltadas a educação ambiental.

Por fim, ressalta-se que a fiscalização e o estimulo a elaboração de instrumentos legislativos e/ou o fortalecimento dos já existentes, com o intuito de consolidar a defesa dessas áreas, a partir de uma perspectiva que preconize o desenvolvimento econômico embases ambientalmente sustentáveis.

$\begin{array}{llllll}\text { Caminhos de Geografia } & \text { Uberlândia-MG } & \text { v. 22, n. } 82 & \text { ago./2021 } & \text { p.102-114 } & \text { Página } 112\end{array}$




\section{REFERÊNCIAS}

ALEIXO, Alexandre; ALBERNAZ, Ana Luisa Mangabeira Kerti; VIVEIROS GRELLE, Carlos Eduardo; VALE, Mariana Moncassim; RANGEL, Thiago Fernando. Mudanças Climáticas e a Biodiversidade dos Biomas Brasileiros: Passado, Presente e Futuro. Natureza \& Conservação, v. 8, n. 2, p. 194-196, Dez. 2010. https://doi.org/10.4322/natcon.00802016

BRASIL. Código Florestal. Lei no 12.651 de 25 de maio de 2012. Diário Oficial da União, Brasilia/DF, 25 de mai. de 2012.

Lei n. .9 .985 , de 18 de julho de 2000. Regulamenta o art. 225, § 10, incisos I, II, III e VII da Constituição Federal, institui o Sistema Nacional de Unidades de Conservação da Natureza e dá outras providências. Diário Oficial da União: Brasília, 2000.

. Lei $n^{\circ} 4771$, de 15 de setembro de 1965. Institui o Código Florestal. Diário Oficial Da União, Brasília/DF, 28 de set. de 1965. Seção 1, p. 9529.

CÂMARA, G. e DAVIS, C. Introdução. In: CÂMARA, G.; DAVIS, C. e MONTEIRO, A. M. V. (Ed.). Introdução à Ciência da Geoinformação. São José dos Campos: INPE, 2003

DEAN, W. A ferro e fogo: a história e a devastação da Mata Atlântica brasileira. 1. ed. São Paulo: Cia. das Letras, 1996.

EUGENIO, F.C et al. MAPEAMENTO DAS ÁREAS DE PRESERVAÇÃO PERMANENTE DO ESTADO DO ESPÍRITO SANTO, BRASIL. Ciênc. Florest. Santa Maria, v. 27, n. 3, p. 897906, Set. 2017. https://doi.org/10.5902/1980509828639

FERRETTI, O.E. Áreas protegidas na ilha de Santa Catarina, Florianópolis, Brasil. Acta Geográfica, Boa Vista, v.13, n.31, p.66-89, jan/abr, 2019.

INSTITUTO BRASILEIRO DE GEOGRAFIA E ESTATÍSTICA (IBGE). Censo Demográfico 2010. Rio de Janeiro: IBGE, 2010.

INTERNATIONAL UNION FOR CONSERVATION OF NATURE AND NATURAL RESOURCES (UICN). Guidelines for Applying Protected Area Management Categories. Gland: UICN, 2008.

LUPPI, A. S. L. et al. Utilização de Geotecnologia para o Mapeamento de Áreas de Preservação Permanente no Município de João Neiva, ES. Floresta Ambient., Seropédica, v. 22, n. 1, p. 1322, Mar. 2015. https://doi.org/10.1590/2179-8087.0027

MACEDO, S.A; MOREAU, M.S. Mapeamento dos Manguezais do Município de Cairu-BA, Utilizando Classificação Orientada a Objetos e Imagem LANDSAT 8. In: PINHEIRO, L.S; GORAYEB, A. Geografia Física e as Mudanças Globais. 1.ed. Fortaleza: UFC, 2019.

NUNES, J. F., ROIG, H. L. Análise e mapeamento do uso e ocupação do solo na bacia do Alto Descoberto, DF/GO, por meio de classificação automática baseada em regras de lógica nebulosa. Revista Árvore, Viçosa-MG, v.39, n.1, p.25-36, 2015.

https://doi.org/10.1590/0100-67622015000100003

OLIVEIRA, F.F.G Aplicação das técnicas de geoprocessamento na análise dos impactos ambientais e na determinação da vulnerabilidade ambiental no litoral sul do Rio Grande do Norte. Rio Claro/SP, 2011 (Doutorado em Geociências e Meio Ambiente/UNESP).

OLIVEIRA, T. G.; FRANCISCO, C. N. Mapeamento das Áreas de Preservação Permanente e as Mudanças no Código Florestal. Caderno de Geografia, v. 28, n. 54, p. 574-587, 2018. https://doi.org/10.5752/P.2318-2962.2018v28n54p574-587

PREFEITURA MUNICIPAL DE TIBAU DO SUL (PMTS). Lei Municipal № 383, de $\mathbf{3 1}$ de Dezembro de 2008. Dispõe sobre a Política Municipal de Meio Ambiente e o Código do Meio Ambiente do Município de Tibau do Sul e cria o Sistema Municipal de Meio Ambiente, Tibau do Sul/RN, 2008. 
RIBAS, Rodrigo Pinheiro; GONTIJO, Bernardo Machado. Mapeamento dos Limites Oficiais do Mosaico de Áreas Protegidas do Espinhaço: interatividade entre o geoprocessamento e a gestão integrada do território. RBC. Revista Brasileira de Cartografia (Online), v. 67, p. 1641-1650, 2015.

SOARES, Vicente Paulo et al. Mapeamento de áreas de preservação permanentes e identificação dos conflitos legais de uso da terra na bacia hidrográfica do ribeirão São Bartolomeu - MG. Rev. Árvore, Viçosa, v. 35, n. 3, p. 555-563, jun. 2011. https://doi.org/10.1590/S0100$\underline{67622011000300018}$

RIO GRANDE DO NORTE. Governo Estadual. Lei no 6.950, de 20 de agosto de 1996. Dispõe sobre o Plano Estadual de Gerenciamento Costeiro e dá outras providências. Natal, 1996.

Governo Estadual. Lei no 7.871, de 20 de julho de 2000. Dispõe sobre o Zoneamento Ecológico-Econômico do Litoral Oriental do Rio Grande do Norte e dá outras providências. Natal, 2000.

Recebido em:29/06/2020

Aceito para publicação em: 16/09/2020 